\title{
Investigation of viscous characteristics of ice cream mixtures with starch syrup
}

\section{Oksana Bass ${ }^{1}$, Galina Polischuk ${ }^{1}$, Elena Goncharuk ${ }^{2}$}

\author{
1 - National University of Food Technologies, Kyiv, Ukraine \\ 2 - Chuiko Institute of Surface Chemistry of National Academy of Sciences of \\ Ukraine, Kyiv, Ukraine
}

Keywords:

Ice cream

Sugar

Syrup

Saccharification

Viscosity

\section{Article history:}

Received 30.03.2017

Received in revised

form 25.04.2017

Accepted 29.06.2017

\section{Corresponding}

author:

Oksana Bass

E-mail:

Kleona@meta.ua

DOI:

$10.24263 / 2304-$

974X-2017-6-2-8

\section{Abstract}

Introduction. Starch syrup is widely used as a sweetener for the production of ice cream, but its structuring ability is not sufficiently studied and requires additional research. Revealing patterns of structuring mixtures with the syrup of different degrees of saccharification allows to reduce the need for structural stabilizers and to achieve a technological effect in the process of ice cream production at the expense of only natural ingredients.

Materials and methods. Rheological characteristics of mixtures of ice cream and aromatic ice cream with glucosefructose syrup (HFCS-96), glucose syrup (HFCS-42) and carotene syrup (HFCS-30) have been investigated by using a rotary viscometer.

Results and discussions. With complete replacement of sugar for starch syrup HFCS-30 and HFCS-42, the initial effective viscosity of ice cream mixtures increases by $22,1 \%$ and $2,5 \%$ respectively, compared to the control sample with sugar. as compared to the control sample with sugar. At the same time, complete replacement of sugar on the syrup HFCS-96 contributes to a decrease in the initial effective viscosity of the ice cream mixture by $15,3 \%$. Initial effective viscosity of aromatic ice cream mixtures at full replacement of sugar by HFCS-30 and HFCS-42 increased by $27,1 \%$ and $14,8 \%$ respectively, and decreased by $11,6 \%$ at full replacement of sugar for HFCS-96 syrup.

Starch syrups HFCS-42 and HFCS-96 provide mixtures of thixotropic properties. Instead, systems with syrup HFCS-30 can not only completely restore the structure, but also show weak reopectic properties. Due to this, in the mode of inverse reduction of the shear rate, the effective viscosity of the mixtures of ice cream of cream and aromatic, in case of complete replacement of sugar, increases by $12,7 \%$ and $18,8 \%$, respectively, compared with the initial values. In mixtures containing a mixture of HFCS96 and HFCS-30 patches at a ratio of 30:70, the effective viscosity increases in reverse slip rate by $9,5 \%$ and $12,5 \%$ for ice cream and aromatic ice cream, respectively, compared to Initial values.

Conclusions. The structuring ability of starch syrup decreases with increasing its degree of saccharification. The revealed pattern of the effect of starch syrup with different dextrose equivalent on viscosity characteristics of mixtures of different chemical compositions makes it possible to purposefully form indicators of ice cream quality. 


\section{Introduction}

The viscosity characteristics of ice cream mixtures change during the technological process under the influence of certain types of thermal and mechanical processing (mixing, pasteurization, homogenization, cooling, maturation, freezing) [1-6]. Thus, scientists at the University of Manchester (UK) have confirmed that the viscosity of ice cream mixtures is volatile and depends, first of all, on the temperature of the samples under study and the rate of shear [2]. Scientists at the Department of Food Science, Faculty of Agriculture, University of Udine (Udine, Italy) have proved the dependence of the viscosity characteristics of ice cream mixtures on the process of homogenization [3].

Existing recommendations on the regulation of structural and mechanical properties of ice cream mixtures chiefly take into account only the effective viscosity of the virtually undamaged structure of mixtures. Thus, for mixtures of ice cream of classical species (milk, cream, plombir) at a temperature of $20^{\circ} \mathrm{C}$ at a shear rate $\gamma=3$ this figure should be about 200, 600 and $1200 \mathrm{mPa} \cdot \mathrm{s}$ respectively. For the aromatic mixtures, effective viscosity is much lower and can reach $250 \mathrm{mPa} \cdot \mathrm{s}$ [5].

In the process of ice cream production, in the period between two technological operations, "freezing" and "quenching", when the structure of a complex food system varies from liquid (mixture) to a practically solid (hardened ice cream), it is equally important that the ability of ice cream mixes to collapse significantly under the action of the external shearing forces of the blades of the stirrer in the frieze and to quickly and effectively restore the structure in a static state after the formation of portions before the quenching process. The structure of the mixture must be partially or completely restored in the formed portion of the finished product, which significantly improves its quality [2,5]. Proper viscosity of the mixtures and the ability to restore it contributes to the formation of a solid structure of ice crystals and the formation of a hard ice cream consistency $[1,2,4,5,18]$. Instead, scientists almost do not pay attention to the ability of mixtures to restructure the structure, in spite of the fact that in ice cream technology this particular characteristic is one of the most important.

Initial relative viscosity of the finished mixtures and its change in the production of ice cream, primarily, are determined by the physical and chemical characteristics of the formulation components [4]. Hydrocolloids and surfactants (stabilizers, emulsifiers and stabilization systems) are essential in the structuring of mixtures for the production of ice cream [5]. Equally important is the content of the fatty component, with the increase in the viscosity of the mixtures also rises [1-7], as well as its chemical composition and degree of conscientiousness. In the course of the latest developments, so-called "low-fat" milk fat substitutes such as starch, starch-lipid compositions, serum protein isolates (WPI), maltodextrins, etc. are becoming increasingly popular. [6-9], whose influence on the organoleptic and structural-mechanical properties of ice cream is still not sufficiently studied.

Sugar and sugar-containing components, in particular starch syrup, also influence the process of forming the rheological characteristics of the mixtures and the finished product [4, 9-14]. The content of reducing agents in the starch syrup is designated as dextrose equivalent (DE): low conversion DE 28-38, intermediate DE 49-58, and high conversion DE 59-96. Ice cream makers usually use liquid or dry corn syrups from DE 28-42 [4, 14]. With a decrease in DE, the sweetness of the molasses decreases, and the structuring ability increases $[5,10,15]$, which should be taken into account when used as part of food systems. At the same time, there is no information on the possibility of complete 
replacement of sugar by starch syrup and its influence on the viscosity characteristics of mixtures for the production of ice cream.

Consequently, taking into account the above, the study of the effect of starch syrup of different degrees of saccharification on the viscosity characteristics of dessert mixtures is a promising scientific direction in ice cream technology.

In view of the above, the purpose of scientific research is to determine the patterns of the influence of starch syrup of varying degrees of saccharification on the effective viscosity of mixtures for the production of ice cream.

\section{Materials and methods}

\section{Materials}

For the comparison of the rheological characteristics of milk-based mixtures for control, the typical formula of ice cream is selected: with a mass fraction of fat $-10 \%$, dry skim milk residue $-10 \%$, sugar $-14 \%$, stabilizing system Cremodan SE $709-0,5 \%$. For the study of ice cream on the basis of sugar syrups, a flavor mixture with a mass fraction of sugar of $28 \%$ and a classical stabilizer (gelatin) in the amount of $0,5 \%$ of the total mass of the mixture was selected as the Control sample.

As a sweetener and a structuring component, molybdenum-fructose syrup (HFCS-96), glucose syrup (HFCS-42), carotene molasses (HFCS-30) and glucose-fructose syrup were used as a syrup of starch dry.

The following designations were adopted.

Mixtures of ice cream:

- Control 1 ( $14 \%$ of sugar);

- Sample No. 1 (7\% sugar + 7\% HFCS-42);

- Sample No. 2 (14\% HFCS-42);

- Sample No. 3 (7\% sugar + 7\% HFCS-96);

- Sample No. 4 (14\% HFCS-96);

- Sample No. 5 (7\% sugar + 7\% HFCS-30);

- Sample No.6 (14\% HFCS-30);

- Sample No. 7 (4.2\% HFCS-96 + 9.8\% HFCS-30);

Mixtures of aromatic ice cream:

- Control 2 (28\% of sugar);

- Sample No. 8 (14\% sugar + 14\% HFCS-42);

- Sample No. 9 (28\% HFCS-42);

- Sample No. 10 (14\% sugar + 14\% HFCS-96);

- Sample No. 11 (28\% HFCS-96);

- Sample No. 12 (14\% sugar + 14\% HFCS-30);

- Sample No. 13 (28\% HFCS-30);

- Sample No. 14 (8.4\% HFCS-96 + 19.6\% HFCS-30).

\section{Preparation of mixture for ice cream samples with starch syrups}

Mixture for ice cream production was prepared according to the classical technological scheme and typical recipes (pasteurization at a temperature of $85 \pm 2{ }^{\circ} \mathrm{C}$ for $2-3$ minutes, cooling to $4 \pm 2{ }^{\circ} \mathrm{C}$, maturity for 12 hours).

In the samples under study, 50 and $100 \%$ of the sugar replacement was performed on starch syrup with different DE and composition (HFCS-96:HFCS-30 = 30:70), the feasibility of which was confirmed by the authors earlier [11]. 


\section{Research of rheological characteristics of ice cream mixtures}

The viscosity characteristics of the ice cream mixtures were determined by removing the curves of the kinetics of deformation (flow), using a rotary viscometer with a measuring system, cylinder-cylinder. Measurements were performed at a temperature of $20^{\circ} \mathrm{C}$. The measuring cylinder (rotor) S1 was selected in such a way that the gradient layer was distributed over the entire thickness of the product layer located in the annular gap of the viscometer gauge. The measurement of shear stress was carried out in twelve values of shear rate $\gamma$ in the range from 3 to $1312,2 \mathrm{~s}^{-1}$ in series with a gradual increase in shear rates at the highest speed for reverse gradual reduction of velocities [12].

\section{Results and discussions}

The dynamics of changes in the effective viscosity of ice cream mixtures of different types for the gradient of the shear rate $\gamma$ in the range from 3 to $1312,2 \mathrm{~s}^{-1}$ in the direct and reverse is determined (Table 2).

Table 2

Rheological characteristics of the studied systems

\begin{tabular}{|c|c|c|c|c|}
\hline Sample name & $\begin{array}{c}\eta_{1} \\
(\gamma=3), \\
\mathrm{m \Pi a} \cdot \mathbf{c}\end{array}$ & $\begin{array}{c}\eta_{2} \\
(\gamma=1312,2) \\
\text { mПa·c }\end{array}$ & $\begin{array}{c}\mathbf{n}_{\mathbf{3}} \\
(\gamma=3), \\
\mathrm{m \Pi a} \cdot \mathbf{c}\end{array}$ & $\begin{array}{c}\tau \\
(\gamma=1312,2) \\
c\end{array}$ \\
\hline \multicolumn{5}{|c|}{ Mixtures of ice cream } \\
\hline Control 1 & 896,92 & 51,35 & 782,11 & 336 \\
\hline Sample No. 1 & 907,64 & 51,72 & 808,42 & 318 \\
\hline Sample No. 2 & 919,12 & 51,55 & 829,53 & 304 \\
\hline Sample No. 3 & 793,56 & 48,12 & 674,46 & 267 \\
\hline Sample No. 4 & 759,91 & 47,51 & 628,93 & 200 \\
\hline Sample No. 5 & 967,63 & 60,63 & 1050,19 & 425 \\
\hline Sample No. 6 & 1095,34 & 64,50 & 1234,31 & 440 \\
\hline Sample No. 7 & 1001,71 & 57,24 & 1097,26 & 370 \\
\hline \multicolumn{5}{|c|}{ Mixtures of aromatic ice cream } \\
\hline Control 2 & 252,30 & 6,21 & 204,54 & 152 \\
\hline Sample No. 8 & 269,82 & 6,66 & 208,96 & 141 \\
\hline Sample No. 9 & 288,61 & 6,91 & 217,57 & 139 \\
\hline Sample No. 10 & 206,43 & 5,73 & 182,32 & 99 \\
\hline Sample No. 11 & 191,55 & 4,84 & 160,45 & 83 \\
\hline Зразок №. 12 & 299,11 & 7,92 & 342,03 & 181 \\
\hline Sample No. 13 & 323,67 & 9,42 & 384,51 & 197 \\
\hline Sample No. 14 & 291,61 & 7,81 & 327,95 & 185 \\
\hline
\end{tabular}

The nature of the structure destruction of the studied food systems in the process of $m$ easuring the effective viscosity is shown in Figure 1 and 2 on the example of a mixture of ice cream and aromatic cream with a complete replacement of sugar on the starch syrup. 


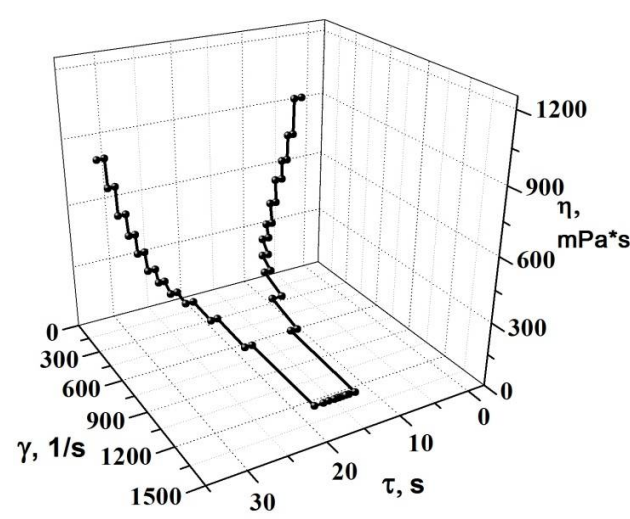

Control 1

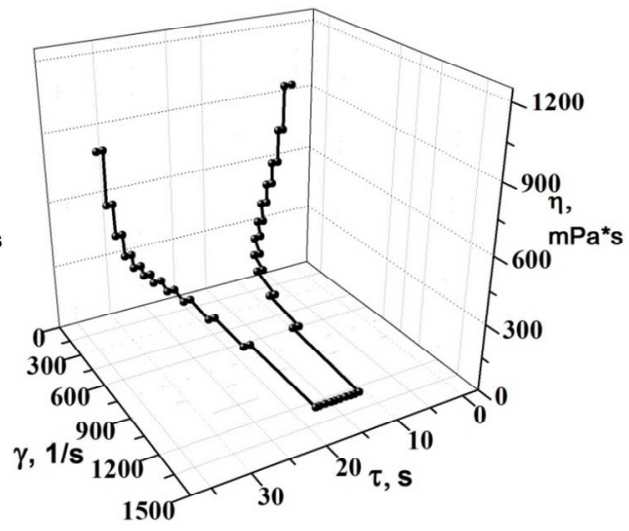

Sample No. 2

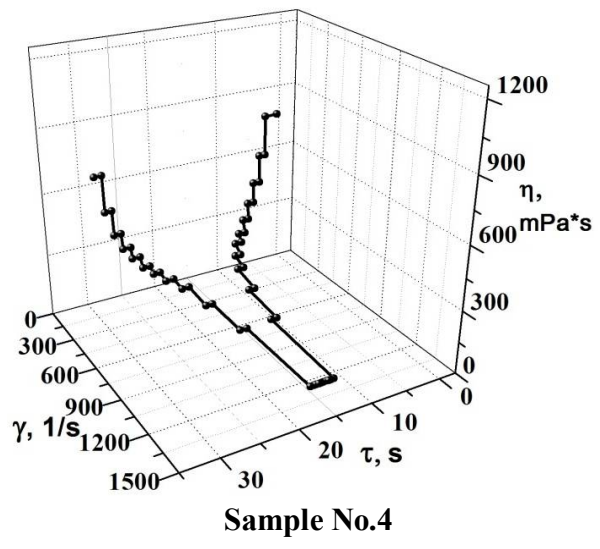

Figure 1. Dynamics of changes in the viscosity characteristics of ice cream cream (Control 1) and samples with $100 \%$ sugar substitution on HFCS-42 (sample No.2) and $100 \%$ sugar substitution

According to the results of the study, it is evident that samples of mixtures of control and mixtures with HFCS-42 and HFCS-96 have thixotropic properties. In the process of rheological research the gradual destruction of the initial structure and the corresponding reduction of the effective viscosity $\left(n_{3}\right)$ by $10,8 \%$ and $17,2 \%$ respectively for ice cream cream and $11,9 \%$ and $16,23 \%$ for aromatic ice cream per $100 \%$-substitutes of sugar compared to their initial values $\left(n_{1}\right)$ are characteristic for them. At the same time, food systems containing HFCS-30, are able not only to almost completely restore the structure, but also to show weak reopectic properties. The latter are manifested in increasing the effective viscosity in reverse shear rate $\left(\eta_{3}\right)$ by $12,7 \%$ for ice cream and $18,8 \%$ for aromatic ice cream at full sugar replacement compared to the initial values $\left(\eta_{1}\right)$. For comparison, in control samples of ice cream and aromatic ice cream with sugar, effective viscosity decreases by $12,1 \%$ and $18,7 \%$ respectively. 


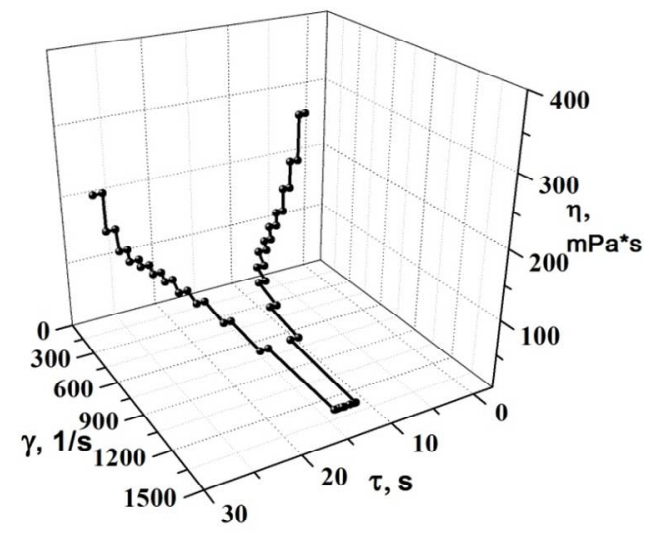

Control 2

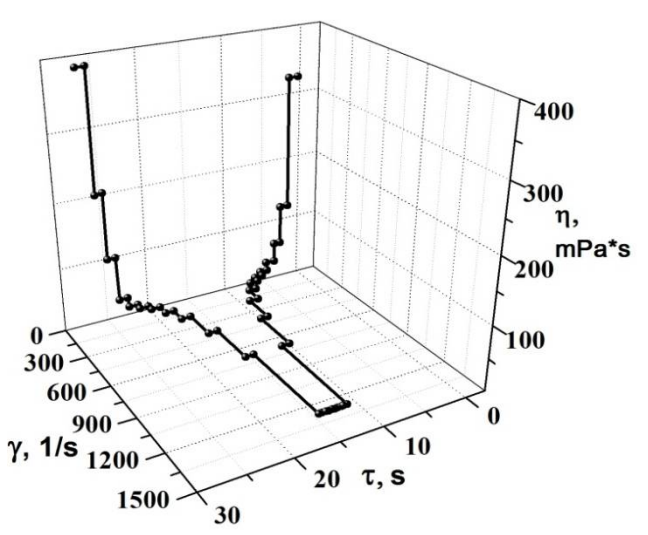

Sample No.13

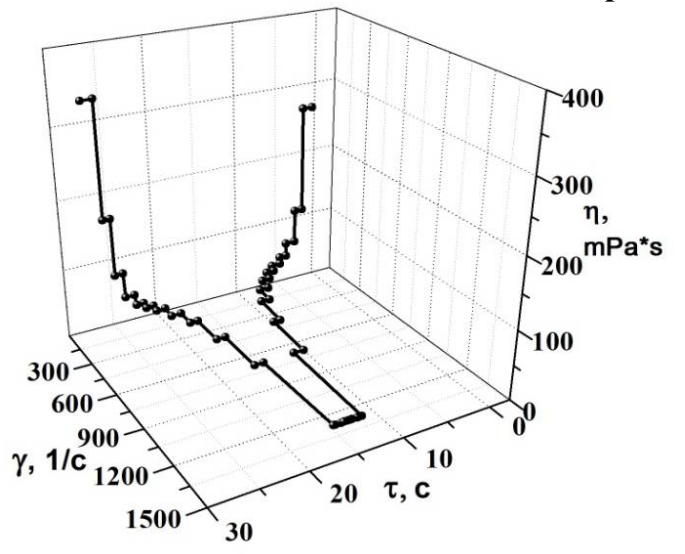

Sample No.14

Figure 2. Dynamic of change of viscosity characteristics of aromatic ice cream (Control 2) and samples with $100 \%$ sugar substitution on HFCS-30 (Sample No.13) and 100\% sugar substitution for a mixture of HFCS-96: HFCS-30 = 30:70 (Sample No.14)

It should also be noted, that in the event of an increase in the degree of saccharification and an increase in the content of mono-sugars in the syrupsmolasses, the time for which the systems under study are transferred to a state of equilibrium $(\tau)$ is reduced.

The use of HFCS-30 at the expense of increased content of polysaccharides not only structures the mixture, but also improves the ability to restore the structure of the formed portions of soft ice cream before quenching. At the same time, the effective viscosity of such mixtures is too high, which can lead to a decrease in the loss of the finished product and the formation of an overly dense structure and coarse consistency of the product $[1,2$, $4,5,18]$. Therefore, the complete replacement of sugar by HFCS-30, taking into account its significant effect on the rheological properties of the mixture for ice cream of various species, is not appropriate. 
The partial and complete replacement of the traditional sweetener by HFCS-96, in turn, contributes to reducing the viscosity of the mixture and the ability to restore its structure, compared with the control sample. Considering the chemical composition of HFCS-96, the effect is due to the predominant content of monosaccharides in its composition [13]. That is, the surplus or lack of polysaccharides does not ensure the proper formation and stabilization of the structure of ice cream.

The food system, which has an overwhelming number of HFCS-30 polysaccharides, compared to HFCS-96 samples, does not provide sufficient structuring, while the use of HFCS-96 alone will provide ice cream with excessive sweetness and low resistance to dandruff $[15,16]$. Therefore, in order to create a structure characteristic for a soft icecream, to balance the taste and consistency of the finished product, it is expedient to use a mixture of starch syrup with a low and high DE for a ratio that ensures the formation of the given physicochemical and organoleptic parameters of ice cream mixtures of different species, in comparison with control samples.

For mixtures with HFCS-96 + HFCS-30 syrup composition for 100\% sugar replacement, an increase in effective viscosity is observed in reverse slope reduction $\left(\eta_{3}\right)$ by $9,5 \%$ for ice cream and $12,5 \%$ for aromatic ice cream compared to the initial values $\left(n_{1}\right)$. It should be noted that the use of the specified starch syrup composition also fully provides the degree of sweetness typical of the classic ice cream. While the replacement of sugar by HFCS-42 slightly affects the rheological parameters of mixtures, but significantly reduces the sense of sweetness.

Similar studies were carried out by the Atatürk University Department of Food Sciences by Cihat Ozdemir, using mixtures for the production of 5\% fat dairy ice cream and a mass fraction of the sweetening component of $18 \%$. As sweeteners in the samples studied, HFCS maltodextrin, HFCS low-soluble molasses, HFCS mixture of medium sugary sugar with a 1:1 ratio, HFCS low-sugar molasses mixture ratio of 1:1 were used in the samples studied. The results of the study showed an increase in the effective viscosity of HFCS low-octane samples and HFCS with an average degree of sacharification of 17,6\% and $2,2 \%$, respectively, for complete replacement of sugar [15]. According to the results of our study, the effective viscosity of ice cream mixtures with HFCS-30 and HFCS-42 increases by $22,1 \%$ and $2,5 \%$, respectively in the case of complete replacement of sugar. Replacing sugar with molasses HFCS-96 contributes to lowering the initial effective viscosity of the cream mixture by $15,3 \%$. Initial effective viscosity of aromatic ice cream mixtures at full replacement of sugar by HFCS-30 and HFCS-42 increased by $27,1 \%$ and $14,8 \%$ respectively, and decreased by $11,6 \%$ with full replacement of sugar for HFCS-96 starch syrup.

These results confirm the general tendency of the influence of the degree of saccharification of syrup on the structural and mechanical properties of the mixtures, but are more versatile due to the nature of the change in the viscosity characteristics of systems of different chemical compositions in the process of mechanical treatment.

The low viscosity of the mixture for aromatic ice cream, as compared with milk-based ice cream, is due to the use of gelatin as a stabilizer. Its macromolecules are not able to form a sufficiently dense framework, compared with the current stabilization system in the ice cream.

The revealed ability of mixtures with starch syrup and polysaccharides in its composition to restore the destroyed structure has practical significance, especially in the case of production of ice cream on the stream extrusion lines, which will improve the efficiency of the process of forming and dosage of ice cream portions. 
In further researches it is planned to study the indexes of quality of ice cream with starch syrup taking into account the results of research of structural and mechanical properties of mixtures for its preparation.

\section{Conclusions}

1. Starch syrup in mixtures for ice cream, depending on the degree of saccharification, significantly affects their structural and mechanical characteristics. The content of higher sugars in the HFCS-30 syrup, unlike HFCS-96, contains the majority of monolysaccharides, contributes to the better structuring of mixtures, which directly affects the increase of their effective viscosity.

2. HFCS-96 and HFCS-42 mixtures are thixotropic, and mixtures with HFCS-30 have low reopectic properties, which allows to predict the dynamics of change in effective viscosity in the technological process of ice cream production.

3. It is expedient to use an HFCS-30 + HFCS-96 composite mixture at a ratio of 30:70 to produce ice cream with high whipping, proper melting resistance and a sufficient degree of sweetness.

\section{References}

1. Wildmoser H., Scheiwiller J, Windhab E.J. (2004), Impact of disperse microstructure on rheology and quality aspects of ice cream, LWT - Food Science and Technology, 37(8), pp. 881-891.

2. P.J. Martin, K.N. Odic, A.B. Russell, I.W. Burns2, D.I. Wilson (2007), Rheology of Commercial and Model Ice Creams, Applied rheology, 18(1), pp. 8-11.

3. Innocente N., Biasutti M., Venir E., Spaziani M., Marchesini G. (2009), Effect of high-pressure homogenization on droplet size distribution and rheological properties of ice cream mixes, Journal of dairy science, 92(5), pp. 1864-1875.

4. Muse M., Hartel R. (2004), Ice Cream Structural Elements that Affect Melting Rate and Hardness, Journal of dairy science, 87(1), pp. 1-10.

5. Goff H.D., Hartel W.R (2012), Ice Cream, Springer US, New York

6. Rolon M. L., Bakke A.J., Coupland J., Hayes J, Roberts R.F. (2017), Effect of fat content on the physical properties and consumer acceptability of vanilla ice cream, Journal of dairy science, 100(7), pp. 5217-5227.

7. Byars J. (2002), Effect of a Starch-Lipid Fat Replacer on the Rheology of Soft-Serve Ice Cream, Journal of Food Science, 67(6), pp. 2177-2182.

8. Aime D.B., Arntfield S.D, Malcolmson L.J., Ryland D. (2001), Textural analysis of fat reduced vanilla ice cream products, Food Research International, 34(2-3), pp. 237246.

9. Akalin, A. S., Karagozlu, C., Unal, G. (2008), Rheological properties of reduced fat and low fat ice cream containing whey protein isolate and inulin, European Food Research and Technology, 227, pp. 889-895.

10. Poliščuk H., Pavlenko O., Bogdanov E. (2015), Sravnitelnyi analiz pokazatelei kachestva morozhenogo s krakhmalnoi patokoi razlichnoi stepeni osakharivaniia, Maisto chemija ir technologija, 49(1), pp. 54-62. 
11. Bass O., Poliščuk H., Breus N., Manoxa L. (2016), Optymizacija skladu morozyva na moločnij osnovi z cukrystymy rečovynamy, Naukovi praci Nacional'noho universytetu xarčovyx texnolohij, 22(1), pp. 166-171.

12. Paszkowski M., Olsztyńska-Janus S. (2014), Grease thixotropy: evaluation of grease microstructure change due to shear and relaxation, Industrial Lubrication and Tribology, 66(2), pp. 223-237.

13. Karaman S., Kayacier A. (2012), Rheology of Ice Cream Mix Flavored with Black Tea or Herbal Teas and Effect of Flavoring on the Sensory Properties of Ice Cream, Food and Bioprocess Technology, 5(8), pp. 3159-3169.

14. Parker K., Salas M., Nwosu V.C. (2010), High fructose corn syrup: Production, uses and public health concerns, Biotechnology and Molecular Biology Reviews, 5(5), pp. 71-78.

15. Ozdemir C. (2008), The effrct of using alnernative sweeteners to sucrose on ice cream quality, Journal of Food Quality, 31(4), pp. 415-428.

16. Bogdanov E. (2008), Ispolzovanie gliukoznykh, maltoznykh, gliukozno -fruktoznykh siropov (patok) pri proizvodstve morozhenogo, Food Technologies \& Equipment: pishchevye tekhnologii, oborudovanie, ingredienty, upakovka, 4-5, pp. 54-59.

17. Herrera M., M Cann J., Ferrero C., Hagiwara T., Zaritzky N., Hartel R. (2007), Thermal, Mechanical, and Molecular Relaxation Properties of Stabilized Frozen Sucrose and Fructose Solutions, Food Biophysics, 2(1), pp. 20-28.

18. Adapa S., Dingeldein H., Schmidt K.A., Herald T.J. (2000), Rheological properties of ice cream mixes and frozen ice creams containing fat and fat, Journal Dairy Science, 83(10), pp. 24-29.

19. George, E., Inglett, Diejun, C., Sean, X. L., Suyong, L. (2014), Pasting and rheological properties of oat products dry-blended with ground chia seeds, Food Science and Technology, 55, pp. 148-156. 